\title{
La merced del oficio de Maestro Mayor
}

\author{
Maria Victoria Garcia Morales
}

Un capitulo importante de la arquitectura del siglo XVII lo constituyen las obras llevadas a cabo por la Corona.

Si los reyes de la casa de Austria velan por mantener la integridad de los territorios del Imperio como si fueran Patrimonio de su herencia, ¿cómo no iban a vigilar y recrearse en el cuidado de sus posesiones particulares?

La serie de noticias que presentamos asi lo demuestran, aunque a veces la realidad, descrita por los viajeros que visitan en este tiempo la Península, revelase abandono y descuido en muchos parajes ${ }^{1}$. Sin duda se debe a la constante falta de recursos económicos más que a negligencia y falta de celo en los reyes.

Para cumplir sus objetivos se establece en 1545 la Junta de Obras y Bosques, máximo organismo para el gobierno y justicia de los Sitios Reales y se dictan normas para su buena administración.

Estas normas para funcionamiento de las Obras Reales parten, en el siglo XVII, de las Instrucciones promulgadas en 1615 por Felipe III2: $^{2}$ :

“... La orden que es nuestra voluntad que se guarde y cumpla en la continuación y ejecución de las obras de nuestro Alcázar de esta villa de Madrid y en la casa del Pardo y Campo y estanques y otras casas y obras que en contorno de esta dicha villa y del Pardo se hacen y se hicieren de aqui adelante entretanto que no proveyéramos otra cosa en contrario o no mudáramos lo contenido en esta instrucción en todo o en parte...".

\footnotetext{
1 J. Garcia Mercadal: Viajes de extranjeros por España y Portugal. Madrid, 1962.

? J.Ma. AzCARATE RISTORI: "Instrucción para las construcciones reales en el siglo XVII". Boletin del Seminario de Arte y Arqueologia de Valladolid. 1959-60. Archivo Palacio. Cedulas. T. XI, págs. $480-486$.
} 
Estas disposiciones son la pauta para los lugares enumerados, así como también para las reales posesiones de: Heredamiento de Aranjuez, Aceca, Valdajoz y Alhóndiga, Alcázar de la ciudad de Toledo, Casas Reales de la ciudad de Valladolid ${ }^{3}$, Castillo de Burgos, fortaleza de Simancas, palacio de Tordesillas, Abrojo y la Quemada, Alcázar de la ciudad de Segovia, Casa Real del Ingenio de la Moneda, Fuenfría y Balsaín, etc.

Constan de 16 puntos y en ellas se van desgranando los deberes, responsabilidades y obligaciones de todos los oficios relacionados con obras, desde un punto de vista fundamentalmente administrativo: veedor y contador, pagador, maestro mayor, aparejador, sobreestantes, tenedor de materiales, etc.

Los cargos $u$ oficios que se contemplan en esta Instrucción vienen de antiguo, probablemente hizo necesaria su promulgación la orden de Inspección (1613) de las Obras del Alcázar de la villa de Madrid y Casas Reales de su entorno 4 .

En ella se dice: “... si los susodichos (oficios enumerados) han procurado que nuestra hacienda sea bien guardada, aprovechada y conservada o si han sido negligentes en ello...". En la resolución de esta Inspección se advierte que ha habido dejación en el cumplimiento de la normativa.

De la lectura de la Instrucción General puede deducirse el papel que desempeña cada uno de los oficiales y principalmente el interés del Rey por la obra de arquitectura «... porque no redunde en daño y perjuicio de la perpetuidad y ornato de las dichas obras de que nos desplaceria mucho...".

Esta Instrucción de 1615, con ligeras modificaciones para los diversos sitios, rige durante todo el siglo 5 . De nuevo se hace referencia a esta Instrucción en 1766 en el documento de contestación a la información pedida por el duque de Medinaceli, Mayordomo de Su Majestad, sobre la administración, funcionamiento y nombramiento en las Casas Reales ${ }^{6}$.

Se pone de manifiesto la vigencia hasta fecha tan tardia, con mayor o menor rigor, de la organización de las obras reales según el modo establecido por la Casa de Austria, pues hasta fecha muy próxima a este informe (1768), la Junta de Obras y Bosques no quedará suprimida. Sus competencias serán asumidas por la Secretaría de Estado?, revelando el nuevo papel de la arquitectura cortesana en el tiempo de los Borbones.

3 A.P. Cédulas. T. XIV, págs. 251 y ss.

${ }^{4}$ A.P. Cédulas. T. XI, págs. 284 y ss.

${ }^{5}$ Ratificada en 1697.

6 Archivo Histórico Nacional. Consejos. Obras y Bosques, leg $^{\circ} 49532$.

7 B. BLasco Esouivias: Catálogo de la Exposición «El Real Sitio de Aranjuez y el Arte Cortesano del siglo XVIII'. Comunidad de Madrid, 1987, págs. 271-286. 
Durante el siglo XVII el organismo del que depende todo lo relacionado con la construcción, mantenimiento y continuación de las obras de la Casa Real es la Junta de Obras y Bosques. Por ella pasa todo lo relacionado a la administración y gobierno, justicia y gracia, eleva propuestas al Rey y es éste quien en última instancia decide, dictamina, pero siempre existe un informe de la Junta de Obras y Bosques.

La decisión real queda plasmada en la llamada Cédula Real, por la que el monarca dicta la norma, nombra, promulga. Constituyen, por esta razón, las Cédulas Reales, una fuente inagotable de noticias y datos, pues en ellas pueden encontrarse: nombramientos o títulos para el ejercicio de un oficio, sus competencias y responsabilidades, ampliaciones del Patrimonio, mecanismo de elección, salarios, permisos, asuntos de justicia y mercedes.

El estudio de estas fuentes nos permite presentar a los arquitectos que fueron Maestros Mayores del Alcázar de la Villa de Madrid y Casas Reales de su entorno del Pardo y Campo, Monasterio de San Lorenzo el Real durante el siglo XVII. Es curioso señalar que el Buen Retiro se considera siempre por separado, para él se nombran Maestros Mayores y se dictan Instrucciones de gobierno ${ }^{8}$, asimismo no está bajo la jurisdicción de la Junta de Obras y Bosques ${ }^{9}$.

Madrid, sede de la Corte desde los primeros años del siglo, constituye un núcleo importante de actividad constructiva con el consiguiente movimiento de artistas. Se construye para el rey y para el engrandecimiento de la Vill ${ }^{10}$, en varias ocasiones la Maestría Mayor de ambas instituciones la ejercerá la misma persona.

Es la Corte el centro de donde emana toda orden de construcción y cuidado de las distintas Casas Reales de todo el territorio y la organización de sus obras sirve de referencia para el resto.

Los cargos que se dan en Madrid no se limitan a Maestro Mayor y Aparejador, sino que existen Aparejador primero y segundo, además del Ayuda de Trazador Mayor ${ }^{11}$.

Trazador Mayor es el Maestro Mayor del Alcázar de Madrid, la dualidad de cargos está bien señalada en los títulos. Este "oficio" de trazador

8 A.P. Cédulas. T. XIII, págs. 144 y ss.

${ }^{9}$ A.P. Cédulas. T. XVII, pág. 131.

$10 \mathrm{~V}$. Tovar Martin: Arquitectura Madrileña del siglo XVII. instituto de Estudios Madrileños. Madrid, 1983.

R. GuerRA de la Vega: Historia de la Arquitectura en el Madrid de los Austrias, 1516-1700.

1 Aparejador $2^{\circ}$ : Pedro de la Peña. T. XIV, pág. 151 v.; Aparejador $1^{\circ}$ : Bartolomé Hurtado. T. XV, pág. 287; Ayuda de Trazador: Blas Carbonell. T. XIII, pág. 328. En A.P. Cédulas. 
permite dar trazas para todas las obras reales y es la gran diferencia con los nombramientos de Maestros Mayores para otros sitios reales, en los que es habitual encontrar "... guardando en todo las órdenes e instrucciones que están dadas o se dieren adelante y siguiendo las trazas que para la continuación de las dichas obras estuvieren hechas o se hicieren...".

El siglo se inicia con la presencia de Francisco de Mora ocupando este cargo entre otros muchos de los de la Corte. El 11 de febrero de 1611 nombra el rey, «...por Maestro de las dichas obras y Trazador de ellas..." a Juan Gómez de Mora, "...su sobrino nuestro criado acatando la habilidad y suficiencia y lo que nos ha servido y sirve...". Las obligaciones o funciones que se le marcan en el título son "...como tal ordene lo que se hubiere de hacer en ellas en los reparos que yo mandare hacer...", "...firme las nóminas y libranzas de lo que se gasta...", "... tenga una llave del arca en la que se metiere el dinero...", y “... haga los remates y conciertos de los destajos...", "... con intervención y parescer de los demás oficiales de dichas obras como se ha acostumbrado y lo hacia y podia hacer el dicho Francisco de Mora...". Cuando en el título, indica que en sus ausencias el Aparejador sea el que le sustituya en sus funciones añade que todo lo consulte con el Maestro Mayor y a...guarde y ejecute la orden que él le diere en lo tocante a ellas...". Como salario le adjudica 200 ducados de los que gozará "... habiendo hecho primero juramento...".

Es interesante resaltar el juramento que por esta cédula está obligado a hacer y que figura al margen de la misma y como alli consta está tomado de manos de Juan de Ibarra, secretario de la Junta de Obras y Bosques y que dice lo siguiente:

\footnotetext{
"... Yo, Juan de Ibarra del Consejo de su Majestad en el Real de Indias y su Secretario de Obras y Bosques certifico que en la Villa de Madrid a catorce de febrero de 1611 años Juan Gomez de Mora a quien su Majestad ha hecho merced del oficio de Maestro y Trazador de las reales obras como se contiene en la cédula de esta otra parte ha hecho el juramento que ella demanda en mis manos de que bien fiel y lealmente servirá a su Majestad en los dichos oficios y que donde viere provecho de su Real hacienda lo procurara y donde viere o entendiere daño della lo escusara en cuanto pueda...".
}

Destacamos, pues, la dualidad de oficios que supone el ser por una parte Maestro Mayor y por otra Trazador. Las funciones que señala en cuanto el rey ordena lo que se ha de hacer, es el comitente, y el maestro el responsable del cómo hacerlo, es decir es el responsable de la realización de la obra, tanto de los planos como de la fábrica.

En 1648, habiendo fallecido Juan Gómez de Mora nombra el rey por 
Maestro Mayor y Trazador de las obras a Alonso Carbonel ${ }^{12}$. En su nombramiento, que en cuanto a funciones es exacto al de Juan Gómez de Mora, y en el de todos sus sucesores en el cargo, resaltan las siguientes palabras, “... con intervención y parescer de los demás oficiales de dichas obras como se ha acostumbrado a hacer y lo hacía y podía hacer el dicho Juan Gómez de Mora precediendo orden para ello del Superintendente que es o fuere de ellas o de la persona que por su ausencia hiciera este oficio conforme en esta presente tengo resuelto sin cuya comunicación y licencia no se ha de poder hacer obra ni librar cosa alguna no habiendo orden espresa mia para lo contrario...." ${ }^{13}$. El resto es similar al título anterior a excepción del salario que se eleva a 400 ducados al año, "...que tenía y gozaba el dicho Juan Gómez de Mora su antecesor...". Es decir, en medio siglo se había duplicado el salario, pero en lo restante de siglo permanecería inalterable en los dichos 400 ducados.

La figura del superintendente máxima autoridad administrativa de las obras a las que el Maestro Mayor, Veedor y Contador deben someterse aparece, asi señalada a partir del nombramiento de Alonso Carbonel.

Es cargo que en las diversas ratificaciones de las Instrucciones de 1615 aparece y desaparece, sus amplias competencias entran en litigio con la Junta de Obras y Bosques. Las noticias sobre este oficio se suceden a lo largo del siglo por lo que será objeto de un próximo artículo, ahora dejamos constancia de que el puesto de superintendente si bien no tenía influencia directa en cuanto al cómo desarrollar una obra sí intervenia en las asignaciones y todo lo relacionado con la administración, pudiendo en determinados casos llegar a mediatizar el trabajo del resto de los oficiales.

Retomando los Maestros Mayores del Alcázar de Madrid y Casas Reales de su contorno, los nombramientos se suceden sin que las Cédulas Reales correspondientes aporten nada nuevo a lo dicho. Los nombramientos de José Villarreal (1660) ${ }^{14}$, Sebastián Herrera ${ }^{15}$ (1661), Gaspar de la Peña $(1671)^{16}$ reconocen los distintos cargos que ocupan en el momento de su nombramiento; asi en Villarreal se le reconoce como "... ayuda de mi furriera y atendiendo a su habilidad y suficiencia y a lo que me ha servido y sirve de más de veinte años a esta parte en los oficios de Aparejador y Ayuda de Trazador Mayor...", en Sebastián Herrera “... atendiendo

12 A.P. Expediente personal Ca $200 / 3$.

13 A.P. Cédulas. T. XIV, pág. 190.

14 A.P. Exp. personal Ca 1101/5. Cédula. T. XV, pág. 94.

15 A.P. Exp. personal Ca 507/40. Cédulas. T. XV, pág. 140.

${ }^{16}$ A.P. Exp. personal Ca 802/26. Cédulas. T. XV, páq. 386. 
a su habilidad y demás buenos requisitos que en él concurren y a la buena cuenta que ha dado en muchas casas de mi servicio que han corrido por su mano a imitación de su padre Antonio Herrera que me sirvió con particular aprobación largos años...". En todos se les nombra Maestro Mayor y Trazador de ellas, se les exige para poder ejercer que hagan juramento y se les supedita al superintendente. El salario como se ha indicado permanece invariable en 400 ducados. El resto es exacto de unos nombramientos a otros.

Sucede a Gaspar de la Peña en el cargo Francisco Herrera Hinestro$\mathrm{sa}^{17}$, pero en este punto hay que aclarar lo siguiente:

La Cédula Real de 3 de septiembre de 1687 dice textualmente:

“... Por cuanto habiendo hecho merced a Joseph del Olmo en catorce de Junio del año pasado de mil y seiscientos y setenta y seis del oficio de Maestro Mayor de las obras del Alcázar desta Villa de Madrid y casas reales de su contorno que vaco por muerte de Gaspar de la Peña de que no saco título para servirle; tuve por bien de nombrar a Don Francisco Herrera para que la sirviera y habiendo fallecido estandolo haciendo he resuelto volver a elegir al dicho Joseph del Olmo en atención a sus servicios para que sirva el dicho oficio de Maestro Mayor..." ${ }^{18}$.

El resto de la cédula continúa como es habitual en estos casos y en los mismos términos de siempre, con cita al superintendente, mención al juramento y al mismo salario. En el margen de la Real Cédula puede leerse: «... Hizo en mis manos Joseph del Olmo el juramento que en este título se manda, Don Bernardino de Aranda y fue el mismo dia de su fecha...".

Lo anterior nos demuestra que podía muy bien no tomarse posesión de un oficio por más que hubiera nombramiento real. Asimismo queda claro que el último Maestro Mayor de las Obras reales y Trazador de ellas fue José del Olmo cuyo nombramiento efectivo fue por Cédula Real del 3 de septiembre de 1687, gozando del dicho salario desde del 30 de julio del mismo año.

El perfil que de este oficio presentan las instrucciones generales y las diversas cédulas de otorgamiento de títulos se puede resumir en que es una figura fundamental para la administración de las obras y especialmente para el control del gasto en las obras reales. $\mathrm{Si}$, como se desprende de la lectura de las instrucciones, son tres las personas sobre las que descan-

17 A.P. Exp. personal Ca 2637/13. Cédulas. T. XVI, pág. 69.

18 A.P. Exp. personal $C^{a} 756 / 14$. Cédulas. T. XVII, pág. 51 v. 
sa el entramado administrativo de una obra: Veedor y Contador, Maestro Mayor y Pagador se puede afirmar que junto con ellos se sitúa en el nivel organizativo y de control más alto, compartiendo responsabilidades: «...el veedor y contador junto con el maestro mayor se junten con el pagador a ver y conferir como está el cargo del dicho pagador...", "...que el dicho maestro mayor tenga una de las tres llaves del arca donde se ha de guardar el dinero...", se indican reuniones de los tres para ver la marcha de las obras y dar cuenta y acordar con el secretario de la Junta de Obras y Bosques "...todo to hecho en la semana y resolver en la siguiente...".

Este cargo implica una responsabilidad especifica de dirección: «...los maestros y oficiales canteros... que conviniere que trabajen en ellas los ha de rescibir el Maestro Mayor...", es obligación suya el prever las necesidades de materiales de cualquier clase y la programación diaria del trabajo, señalando a cada uno lo que ha de realizar y que de no hacerlo asi y si por ello las obras sufrieran retraso estaria penalizado. Es decir, el conocimiento completo del proyecto o programa constructivo, lo que compete a la marcha y forma de realizar una obra es de su exclusiva responsabilidad.

Unicamente en el Alcázar de Madrid, como hemos dicho, se les nombra por "... Maestro Mayor y Trazador de ellas...", el oficio de trazador en ninguno de los nombramientos para otros lugares reales se incluye y más aún a éstos se les niega la posibilidad de alterar las trazas que están hechas o se hicieren, obligándose «...a cuidar las trazas...», "...se han de guiar y proseguir la obra sin quitar ni añadir ni alterar cosa alguna ni parte de ella...». Esto supone cierta merma en las facultades del Maestro Mayor, presentándolo no como creador sino como intérprete de lo que se quería hacer.

En términos generales siempre dispone de un Aparejador que le sustituye cuando está enfermo o ausente, pero en lo tocante a las obras el Maestro Mayor se sitúa en un escalón superior al del Aparejador a quien da las órdenes oportunas. Se puede suponer que el ser Maestro Mayor exige una preparación profesional, superior y diferente a la del Aparejador. Ambos proceden de la maestria de obras, la diferencia viene dada por la merced que reciben del rey, por las obligaciones (bien definidas) del oficio o puesto de trabajo al que sirven. Por esto no es extraño encontrar que el Maestro Mayor de un Sitio pase a ser Aparejador en otro, tal es el caso de Pedro Garcia Mazuecos, Maestro Mayor de las Obras reales de la ciudad de Valladolid "... promovido al oficio de Aparejador de las de nuestro Alcázar de la Villa de Madrid...". Y el caso de Alonso Carbonel, Maestro Mayor de las obras del Buen Retiro y Aparejador del Alcázar de Madrid.

El oficio de Maestro Mayor no era cargo que exigiera una exclusividad pues es bastante frecuente encontrar que la misma persona desempeña 
otros oficios, bien dentro de la Corte como Aposentador, Ayuda de la furriera, Mayordomo, etc., bien fuera de ella y en otras instituciones como Cabildos o Ayuntamientos. Esta última circunstancia podría estar relacionada con la presunción de que los nombrados eran los mejores o los más relacionados y conocidos y sobre ellos se daba una acumulación de cargos. 